\title{
Kangaroo Care in a Neonatal Context: Parents' Experiences of Information and Communication of Nurse-Parents
}

\author{
Desirée Lemmen ${ }^{1}$, Petra Fristedt ${ }^{2}$ and Anita Lundqvist ${ }^{*}, 3$ \\ ${ }^{I}$ Skåne University Hospital, Lasarettsgatan 48, Lund, SE-22185 Sweden \\ ${ }^{2}$ Capio Cityclinic, Östergatan 29, Landskrona, SE-261 34, Sweden \\ ${ }^{3}$ Child, Family and Reproductive Health, Department of Health Sciences, Lund University, P.O. Box 157, Lund, SE-221 \\ 00, Sweden
}

\begin{abstract}
Objective: Kangaroo Care (KC) is an evidence-based nursing practice with many benefits for infants and parents. The purpose of this study was to describe parents' experience of information and communication mediated by staff nurses before and during $\mathrm{KC}$ at neonatal wards.

Methodology and Participants: A qualitative study with semi-structured interviews was performed. The sample consisted of 20 parents.

Results: The results show that the information and communication were experienced as both optimal and suboptimal including following categories: initially conflicting emotions in relation to $\mathrm{KC}$, participation and confidence in $\mathrm{KC}$ is evolving, strengthening preparation and context is decisive as well as parental sense and caution. The overall theme was that good preparation will contribute to a positive experience of $\mathrm{KC}$.

Conclusion: The conclusion is that most of the parents had positive experiences of KC. The information and communication from the staff nurses encouraged and motivated the parents to practice $\mathrm{KC}$, in a sense that it was a natural way to get to know the infant, when the staff nurses were well versed in the method and coherent and supportive. Conflicting emotions emerged when staff nurses practised $\mathrm{KC}$ as a routine without deeper knowledge and skills of the method and its advantages as well as without sensitivity to parents' vulnerable situation.
\end{abstract}

Keywords: Communication, information, Kangaroo Care (KC), neonatal, parents experience.

\section{INTRODUCTION}

Of all children who are born each year in Sweden, approximately $90000-100000,4.8 \%$ are born preterm $[1,2]$. A preterm birth is defined as delivery that occurs before 37 weeks of gestation $[1,2]$. About $0.9 \%$ are born at gestational age of 32 weeks and $4.6 \%$ between 33 and 36 weeks [3]. The number of preterm births in Europe and North America are $7.4 \%$ [2]. When the infant is born preterm the infant is taken away from their parents immediately, following the birth for medical assessment and treatment that is described as a crisis for both parents [4, 5]. A preterm infant cared for in a Neonatal Intensive Care Unit (NICU), is associated with highly technical equipment and parents can experience difficulties regarding the experience of that the infant is theirs and that the infant needs them [6-8]. For parents to manage their fears of approaching the small infant, they need to be encouraged to touch their infant. They want to be involved in health care but to venture to come close to their infant the parents need a lot of support from the staff nurses [6-8]). Kangaroo care (KC) is a nursing practice, to some

*Address correspondence to this author at the Child, Family and Reproductive Health, Department of Health Sciences, Lund University, P.O. Box 157, Lund, SE-221 00, Sweden; Tel: +46 2221813; Fax +4642148344; E-mail: Anita.Lundqvist@med.lu.se extent accepted worldwide, to meet newborn infants' important needs for warmth, stimulation, parental contact and love $[9,10]$.

In Europe, $\mathrm{KC}$ is admitted as an evidence-based nursing practice in neonatal care. The guidelines recommend that postnatal care should be conducted so that mother and infant after birth are only separated for the shortest possible time, i.e. that $\mathrm{KC}$ should be implemented as soon as possible after delivery or upon arrival at the neonatal unit. It could be used for up to 24 hours a day, taking into account the infant's and mother's condition [10]. There is no defined optimum length of time to carry out $\mathrm{KC}$, although the WHO [9] suggests 2 hours or more/day. Guidelines for $\mathrm{KC}$ describe the practice of holding a preterm or low birth weight infant in an upright, prone position with skin-to-skin contact against the parents' or relatives' chest, dressed in a nappy, with a blanket or clothes covering the infant [9-11].

$\mathrm{KC}$ has been shown to strengthen the ties between infants and parents regarding parents and infants being more sensitive to each other [12-16]. It is also suggested that parents initially are ambivalent to KC. An ambivalence involving a yearning to have their infant close as well as apprehensions about getting too close to their infant or a fear of hurting the infant [9, 14]. Gradually this ambivalence change into strong feelings of well-being in the experience 
of that $\mathrm{KC}$ was something simple and natural, a deep feeling that was hard to put into words $[14,17]$. The bonding between parents and infant increased as $\mathrm{KC}$ had been provided repeatedly. The parents got a feeling of being able to provide warmth and closeness and experienced that they became involved in the care of their infant [12-16]. KC also developed a sensitivity to the infants signals and active parenting [12-19].

$\mathrm{KC}$ 's impact on the mother has been shown to decrease depressive tendencies as well as that if the method was applied daily the mothers' stress was reduced [18]. Fathers who applied $\mathrm{KC}$ directly after the infant was delivered by a caesarean section became more sensitive to the infant's behavioural signals i.e. the infant cried less, showed more searching and craving activity, as well as increased alertness [20]. Fathers who applied KC at the NICU experienced that it promoted their obvious role in the infant's care. The perception was that they were important in the care of the infant and acting as a primary caregiver [16].

$\mathrm{KC}$ also has positive effects on the preterm infant, i.e. improved sleep and brain development as well as less pain responses [21, 22], earlier initiation of breast feeding [7, 23] and becomes easier to settle [16]. A meta-analysis showed that $\mathrm{KC}$ also significantly reduces mortality among infants with a birth weight $<2000 \mathrm{~g}$ and reduces morbidity of major illness, especially caused by infections [24].

Information about the infant's condition and procedures in the neonatal unit as well as the care of the infant are requirements that need to be met for parents to feel comfortable with $\mathrm{KC}[8,13]$. Mothers have an essential need for nurses to guide the $\mathrm{KC}$ experience $[15,19]$ to allay their anxiety about handling the infant and to promote confidence in using $\mathrm{KC}$ [12]. They also need support for $\mathrm{KC}$ with encouragement, teaching, and planning from staff nurses [19]. Some mothers experienced that they had not received enough information about $\mathrm{KC}$ and others experienced the information as being too extensive, with difficulties recollecting the information. The attitude of staff nurses during $\mathrm{KC}$ were sometimes negative that made mothers doubtful [17]. Being offered options of asking other persons to participate in the provision of $\mathrm{KC}$ at the NICU was also inadequate and staff nurses lacked sensitivity to mothers' needs and wishes regarding KC [15]. Fathers experienced that staff members made conflicting statements and displayed conflicting behaviour leading to a worry about which $\mathrm{KC}$ rules would apply during the next shift or what was expected of them as fathers. Communication between staff nurses and between work shifts was perceived as poor. This was associated with giving the fathers a feeling of uncertainty to perform certain aspects of the infant's care and difficulty in controlling the infant and feel comfortable in the situation [16].

The purpose of this study was to describe parents' experience of information and communication mediated by health care staff before and during $\mathrm{KC}$ at neonatal units.

\section{MATERIALS AND METHODOLOGY}

A qualitative design was employed i.e. a reflection of the researcher's desire to have the inquiry based on the realities of those under study [25]. The overall aim was to produce condensed and brief descriptions of the parents' experiences of $\mathrm{KC}$ especially regarding information and communication during the hospital stay when having given birth to a preterm infant.

\section{Setting}

The study was performed at three hospitals in southern Sweden of which one carry out neonatal care level IV (University hospital with fully developed intensive care) and the two other hospitals at level III (County hospitals with partial neonatal intensive care [26]). KC was introduced as a care method in all hospitals. Included in the study were healthy primi- and multiparous women and their cohabitants.

\section{Participants}

The women should have delivered an infant, $24+0$ to $35+0$ gestational weeks, who did not have a life-threatening condition and the informants having a good knowledge of the Swedish language. The mothers and fathers, who had experienced $\mathrm{KC}$ from birth to discharge during the period March to December, 2009, were invited to participate in the study. After the infants discharge from the hospital the parents who had consented to participate were approached by a phone call and asked if they still agreed to participate: a time and place for the interview was reserved. Twelve families chose to participate in the study. The participating families represented fifteen neonates while three of the families had given birth to twins. Four of the fathers declined participation because of lack of time. In five of the twelve families, one parent (three mothers and two fathers), did not have Swedish as their native language but had good knowledge in Swedish. The foreign-born came from Denmark, Germany, Montenegro, Norway and United Kingdom. Out of the families five had stayed at more than one hospital due to the fact, that the infant needed level IV care or that the delivery started when the parents were away from home. The infants' gestational age ranged from $24+5$ to $34+4(\mathrm{M}=30+5)$ including one infant $24+5,25+5$, $32+3,33+2,33+5,34+5$ and three infants $28+0$ as well as two infants $33+0,33+1$, representing six girls and nine boys.

\section{Data Collection}

The authors who collected the data (the first and second author) were registered nurses and mothers of small and older children and had worked in neonatal units a few years where $\mathrm{KC}$ was introduced. The third author has extensive experience of work and research with infants and parents. During the interviews the authors strived to maintain an open, reflective stance, suppressing the own experience by posing open questions and seeking clarification of what was expressed by the parents by an open atmosphere. The interviews lasted 20 to 75 minutes. Eleven of the interviews were conducted by the two authors and one interview was conducted by one author due to interview time being modified by the family on short notice. All interviews were tape-recorded and transcribed verbatim.

The participants had been discharged/released from the neonatal unit between one to four weeks prior to the time of the interview. The main topics during the interviews were: Staff information and communication with parents before and during provision of $\mathrm{KC}$ and the feeling of holding their infant skin-to-skin. All interviews took place in the family home and mothers and fathers were interviewed together 
while the mother was interviewed alone when the father could not attend due to time constraint. All was according to the parents' wishes.

\section{Data Analysis}

The transcribed interviews were analysed by a modified content analysis on the basis of Graneheim and Lundman [27] but modified according to the below description. Initially, all interview texts were read several times to get a general impression. The interview texts concerning the birth were not included in the analysis. The interview texts were divided into meaning units i.e. words, sentences or paragraphs containing aspects related to each other through their content and context [27]. The meaning units were condensed i.e. a process of shortening while still preserving the core and abstracted to codes. The codes were placed under each other for information and communication before and during the $\mathrm{KC}$ and thereafter sorted based on similarities, differences and patterns that formed subcategories. The sub-categories that emerged were: no information/communication; good information/communication; consistent and inconsistent information/communication; and positive emotions, negative emotions and strengthened parents-infant connection while providing $\mathrm{KC}$. The subcategories were joined into categories of similar nature i.e. a group of content that shares a commonality [28]. The final step in the analysis was to interpret the contents of the subcategories to show the underlying meaning of the interviewees' narratives and to deepen the understanding. This resulted in four categories and one overall theme (Table 1). Finally, the interview texts were read again to make sure that the overall theme and the categories covered the interview texts. Discussion among the authors continued throughout the whole analysis process until agreement was reached. The study was also critically examined in seminars with fellow students and researchers.

\section{Ethical Considerations}

The study was conducted in accordance with ethical guidelines regarding the information and consent requirement, confidentiality and data protection [29]. Participants were informed that participation was completely voluntary, and without affecting any eventual further contact with the neonatal care unit and that participation could be discontinued at any time without cause. All participants signed a consent form. If families during the interviews were perceived to have a need to further process their experiences from the neonatal care was a counsellor at each neonatal unit available. The study was approached by The Advisory Committee for Research Ethics in Health Education, Department of Health and Sciences, Faculty of Medicine, Lund University, Sweden, (53-09).

\section{RESULTS}

From the content analysis of interview data following categories and theme emerged. The four categories identified for information and communication were: Initially Conflicting Emotions in relation to KC, Preparation and Confidence in $\mathrm{KC}$ is Evolving, Strengthening Preparation and Context is Decisive, and finally Parental sense and caution. The overall theme was: Good verbal and practical preparation will contribute to a positive experience of $\mathrm{KC}$.

\section{Initially Conflicting Emotions in Relation to KC}

When labour unexpectedly started too early, the neonatal nurse, who was called to the maternity ward, sometimes provided information on $\mathrm{KC}$ before birth. Such information gave conflicting emotions because it gave a sense of being prepared for what would happen when the infant was born. It was also perceived as unimportant information because the parents were only interested in whether the infant would survive, or not.

\section{"...My experience told me this [KC] was not right ... so before caesarean section [in the meeting with a neonatal nurse], I was worried about it ..." (F8, Dad).}

All parents did not remember if they received any information about KC. Initially it was given so much information, making it impossible to remember everything.

Some parents initially upon arrival at the neonatal unit, got information about that $\mathrm{KC}$ was a method that was provided at the unit and that it involved that parents had to

Table 1. Showing Parts of the Analysis

\begin{tabular}{|c|c|c|c|c|}
\hline Meaning Unit & Condensation & Code & Category & Overall Theme \\
\hline $\begin{array}{l}\text { Ah, at first they said, "Yes, but now it's } \\
\text { probably time to start kangaroo care" } \\
\text { So ... they said only that it was just a good } \\
\text { thing ... we should do it as they did it in the } \\
\text { ward ... then I thought what? What is it? }\end{array}$ & $\begin{array}{l}\text { Got the call to start kangaroo } \\
\text { care but did not understand } \\
\text { what it was. Would do it } \\
\text { because it seemed to be a good } \\
\text { thing to do. }\end{array}$ & $\begin{array}{l}\text { No information } \\
\text { and no } \\
\text { communication }\end{array}$ & $\begin{array}{l}\text { Gradually } \\
\text { participation and } \\
\text { confidence in } \mathrm{KC} \\
\text { was evolving }\end{array}$ & $\begin{array}{l}\text { Good verbal and practical } \\
\text { contribution will } \\
\text { contribute to a positive } \\
\text { experience of } \mathrm{KC}\end{array}$ \\
\hline $\begin{array}{l}\text {... it was not that much, if one considers, } \\
\text { explanation of kangaroo care. I remembered } \\
\text { that I had seen a Kangaroo Care picture on } \\
\text { the wall in the ward. It was just a natural } \\
\text { image, a baby's skin to skin with the parent } \\
\text {... it felt quite OK. ... I thought it was } \\
\text { natural and not wrong. }\end{array}$ & $\begin{array}{l}\text { Not much explanation about } \\
\text { what KC meant or was good } \\
\text { for. The parent had seen a } \\
\text { picture with the heading } \mathrm{KC} \text { in } \\
\text { the ward. Found } \mathrm{KC} \text { as a } \\
\text { natural way of caring for the } \\
\text { infant. }\end{array}$ & $\begin{array}{l}\text { No information } \\
\text { and } \\
\text { Communication }\end{array}$ & $\begin{array}{l}\text { Gradually } \\
\text { participation and } \\
\text { confidence in } \mathrm{KC} \\
\text { was evolving }\end{array}$ & $\begin{array}{l}\text { Good verbal and practical } \\
\text { contribution will } \\
\text { contribute to a positive } \\
\text { experience of } \mathrm{KC}\end{array}$ \\
\hline $\begin{array}{l}\text { It was almost as if I wanted to ask, but did } \\
\text { not ask ... maybe they forgot to tell about } \\
\text { KC because they are working with it all the } \\
\text { time, or because they were so busy }\end{array}$ & $\begin{array}{l}\text { The parents wished they had } \\
\text { got a question about if they } \\
\text { knew what } \mathrm{KC} \text { was. The } \\
\text { parents had patience with the } \\
\text { lack of communication. }\end{array}$ & $\begin{array}{l}\text { No } \\
\text { communication }\end{array}$ & $\begin{array}{l}\text { Strengthening } \\
\text { preparation and } \\
\text { context is decisive }\end{array}$ & $\begin{array}{l}\text { Good verbal and practical } \\
\text { contribution will } \\
\text { contribute to a positive } \\
\text { experience of } \mathrm{KC}\end{array}$ \\
\hline
\end{tabular}


have their infant skin-to-skin on their chest. After a few days they got more in-depth information including for example KC's promotion of the infant's natural temperature regulation, the parents-infant connection, and the mother's breast milk production. The parents experienced that they gradually became familiar with $\mathrm{KC}$ and got their questions answered leading to a desire to be involved in the care of their infant. With this information parents experienced that $\mathrm{KC}$ was quite natural i.e. just as they had planned to care for their newborn infant.

\section{"[Information about] $\mathrm{KC} \ldots$ did that $\mathrm{KC}$ seemed quite natural ... just right ... not something strange for us to do ..." (F2, Mom and Dad).}

Some parents were convinced that they had not received any information about $\mathrm{KC}$, but merely an insistence on holding their infant skin-to-skin on their bare chest. The parents wanted to get close to their infant but there were conflicting feelings towards the abrupt way to approach the infant. The experience was that the staff nurses did not understand the parent's concern about whether the infant would survive and the concern about the preterm birth.

\begin{abstract}
"No, but it was uh ... just so you can take your clothes off, so you can put on this shirt, you should have her skin-to-skin ..." (F11, Dad).

"... It was a bit terrifying and I thought shall we take him out [of the incubator]? But of course that is what you want as a mother, you want to take him out. But it's just that the shock and so, can fold first ..." (F10, Mom).
\end{abstract}

One couple of parents recalled that they were involved in decision making about providing $\mathrm{KC}$ for their infant, while the other parents could not remember if they got such a question, or not. When information about the $\mathrm{KC}$ was given without the staff nurses being able to answer parent's questions the feeling appeared that it was a method that was "in" at the moment.
"... seemed a bit like one of those trendy thing, as well ... as a recent weight loss method ... here we go Atkinson now we are doing something else and so here we go ... no without mentioning that $K C$ was conceived and tested. Important to obtain this information as well ..." (F2 Mom and Dad).

\section{Participation and Confidence in $\mathrm{KC}$ is Evolving}

The parents had experienced that $\mathrm{KC}$ was a nursing practice that staff nurses at the various hospitals applied. Satisfaction with $\mathrm{KC}$ was highest among parents in one of the hospital where the parents had experienced that $\mathrm{KC}$ was well established among all staff nurses i.e. all were familiar with the method's context, benefits and practise. The verbal information was given with enthusiasm and the information and communication were fully consistent, no matter which staff nurse talked with parents, and the parents got answers to their questions. The parents also received written information about $\mathrm{KC}$ and there were posters about $\mathrm{KC}$ on the unit.
"... All [staff] had the same attitude towards it [KC] ... and it's important for us parents ..." (F2, Dad).

At the other two hospitals the staff nurses were perceived as not consistent in terms of information and provision of $\mathrm{KC}$. The information and communication was poor and the nursing staff's focus had been that the parents would have their infant skin-to-skin with no further explanation. The experience was that each of the staff nurses had their way of working with $\mathrm{KC}$. When the parents asked questions about $\mathrm{KC}$ they received vague and conflicting answers. The staff nurses' approach was tolerated of the parents and $\mathrm{KC}$ was provided, on the grounds that there were many infants on the ward and the staff nurses seemed overworked. Another reason for the tolerance was that it was vacation time and the parents concluded that agency nurses were on service, so hence the conflicting communication. Despite the staff nurses' ignorance of $\mathrm{KC}$ all parents experienced great confidence to the staff nurses when it came to the medical and nursing care of their infant. The staff invited the parents to participate in the care by performing tube feeding, diaper change, turning the infant in the bed/incubator, getting the infant to settle down, etc. and this was very satisfying for the parents.

"... There was no consistent approach [in the
information and communication of KC] ... or a
common way of thinking ... it was a lot of
thoughts and thinking ... conflicting advice ...
it came through of the kangaroo method ..."
(F6, Mom).

Sometimes the staff nurses were aware of that parents might have received vague and conflicting information and communication about $\mathrm{KC}$. In this situation the parents were recommended to converse with the contact nurse assigned to them.

"... And that's a good thought ... that you stick to a few people... so that it is not such a mess ..." (F8, Mom).

\section{Strengthening Preparation and Context is Decisive}

Parents' sense of KC was strengthened when the staff nurses communicated with the parents before the $\mathrm{KC}$ holding by preparing the infant so that $\mathrm{KC}$ would become a quiet moment, as the parents wished for. Above all, the mothers wanted help with the preparations of the infant, when $\mathrm{KC}$ was first implemented. When not receiving any information about the preparations the parents observed how the staff was preparing the infant and learned to do it by themselves. The preparations that were considered important were that the infant should not require a diaper change or examinations during the time allocated to $\mathrm{KC}$ due to a desire to get privacy during $\mathrm{KC}$.

Parents experienced a disappointment over not receiving information about KC's important physiological effects regarding to prevent complications for the infant. They demanded that if there was no time for verbal information and communication about $\mathrm{KC}$, there should be written information. Such information also would have facilitated 
the parents understanding of what was expected of them as parents.

\section{"... When they [the staff] take it [KC] seriously ... it helps of course that I take it seriously too and not just because it is cosy, but because it is medically important as well ..." (F12, Mom).}

In order to make $\mathrm{KC}$ to a positive moment for the parents they had wished that the staff had planned $\mathrm{KC}$ carefully as $\mathrm{KC}$ sometimes included several hours of holding the infant. They wanted information about the importance of having eaten before, been to the toilet, having something to drink at hand and above all a comfortable chair to sit in, which was not always available. Some fathers thought it was tedious to implement $\mathrm{KC}$ for several hours at a stretch, but solved it by reading a book or going to sleep.

The information and communication was at times directed only to the mother and the father had felt excluded. These fathers described it as the staff minimized the father's role. When the information and communication was addressed to both parents fathers felt that they were important too for the infant.

$$
\begin{aligned}
& \text { “... KC gave a special feeling ... one became } \\
& \text { more a part of it all ... yes it was special ... for } \\
& \text { me as a dad to got to be like that ... all by } \\
& \text { yourself ... you did something ... than if we just } \\
& \text { sat and slept [during the KC implementation] } \\
& \text {..." (F11, Dad). }
\end{aligned}
$$

Some families received care at more than one hospital due to that the infant was born when the family was not in their home community at the time delivery or the infant needed treatment at a level IV hospital. When the infant later on was transferred to the neonatal unit to which the family's place of residence belonged, the parents experienced that the staff nurses at that hospital had other routines for $\mathrm{KC}$. No information was given of how the routines for $\mathrm{KC}$ were at that hospital and there was no communication regarding the parents $\mathrm{KC}$ provision prior to transfer. Parents lost their own faith to provide $\mathrm{KC}$ in a sense of insecurity when staff nurses did not confirm or did confirm parents' $\mathrm{KC}$ provision.

"... no one said anything ... so directly [about $\mathrm{KC}]$... but we felt ... we're doing something wrong ... it felt pretty uncomfortable ..." (F3, Mom).

\section{Parental Sense and Caution}

The shock and sadness of not having carried the infant full term, was tough for most mothers. When maternal connection to the infant after birth, did not emerge, that led to self-blame, depression and guilt. For these mothers $\mathrm{KC}$ was not always a positive and maternal connection did not appear. The KC-time instead became a routine, which only was done almost mechanically. These mothers were yet of the opinion that $\mathrm{KC}$ had been a support for them. Maternal feelings evolved gradually.

"If all the emotions are not there then you just cannot bother at all times... I did not love my child as I do now ... that how it was ... it [KC] became routine in fact ..." (F3, Mom).
"... It [KC] was probably a good deal because you had to sit close ... was left in peace ...presumably it became apparent [that it was my infant] ..." (F12, Mom).

The parents were surprised that they could have their infant skin-to-skin as soon after birth. When they provided $\mathrm{KC}$ for the first time most often a feeling appeared that they had become parents. The parents wanted to share this feeling and expressed that all new parents would have the opportunity to $\mathrm{KC}$.

"... Everyone should be supposed to come in
to the neo-unit [laughs] a turn [and sit
kangaroo] before going home [laughs]
because that is all positive..." (F1, Mom).

Parents felt that the small infant was fragile and the medical devices that were linked to the infant were frightening. They feared to harm the infant during $\mathrm{KC}$ holding, which was manifested in being reluctant to move their body with the risk that tubes would disconnect from the infant's body or that monitor devices would start alarming and cause distress to the infant. Along with each medical device that was discontinued it became cosier and calmer to provide KC. It was important that there were staff available if something would happen.

"I [the nurse] am sitting here and you [the mother] may be very calm, because this cannot go wrong ..." (F6, Mom).

"To hold my baby [KC] for the first time for real and like to feel his warmth, you felt his fingers, he like touched one ... then you become so happy ... my tears flowed almost constantly during the skin-to-skin holding ..." (F4, Mom).

Most of the mothers experienced $\mathrm{KC}$ as more positive if the father was also present, because then it became an intimate family moment, on the other hand a few mothers experienced that the feeling of closeness to the infant was strengthened if the father was not present. One father had applied KC first when the birth was by Caesarean section and twins were born, where one infant's condition was stable and $\mathrm{KC}$ could be applied before the mother recovered. In this situation the mother experienced dissatisfaction with that the father initially had a deeper connection to the infant then the mother had.

\section{The Overall Theme}

\section{Good Verbal and Practical Preparation will Contribute to a Positive Experience of $\mathrm{KC}$}

The parents lived in chaos and found it difficult to take in information and communicate with the issues in terms of $\mathrm{KC}$. As information and communication on $\mathrm{KC}$ was clear, given with commitment and the staff nurses were safe and unanimous in applying the method, the experience of $\mathrm{KC}$ resulted in a strongly positive experience. Providing $\mathrm{KC}$ was perceived by most parents as a natural way to embrace the infant because they longed to get close to their infant. When staff was perceived to have limited knowledge about the method and did not provide consistent information and were not able to answer parents' questions about $\mathrm{KC}$ parents 
applied $\mathrm{KC}$ anyway and the feeling of $\mathrm{KC}$ was even then positive. Some parents did not immediately have a positive experience of $\mathrm{KC}$ as parental feeling did not appear during $\mathrm{KC}$ holding. The feeling was that the parents needed greater attention and guidance from the staff to gradually overcome their ambivalent feelings for their infant. If $\mathrm{KC}$ would be perceived positively or not was dependent on the infant's medical condition, the father's presence or not presence at the ward, his support of the mother as well as that the staff was available during the $\mathrm{KC}$ provision.

\section{DISCUSSION OF RESULTS AND CLINICAL IMPLICATIONS}

This study examines parents' experiences of information and communication mediated by health care staff before and during $\mathrm{KC}$ at neonatal units. Investigating this is important as it may differ from what the staff nurses believe that parents want and need, and what parents really want and need for being able to provide $\mathrm{KC}$.

When information about $\mathrm{KC}$ is given before birth, conflicting emotions emerge given that parents are in shock and their anxiety over whether their infant will survive is the focus for the parents. Most importantly in this moment is that the staff nurses show sensitivity to the vulnerable situation that parents find themselves in. Similar results are shown in Lundqvist, Hellström and Hallström [6] where the fathers of preterm infants, who are cared for in NICU, find it difficult to take in information about the care of their infant as they found themselves living in an unreality when the infant was born preterm. All parents in our study do not remember if they got any information about $\mathrm{KC}$ at all.

At one of the hospitals, parents experience that there is a clear strategy and implementation of $\mathrm{KC}$ and the parents feel safe with KC and feel trust in staff nurses. The staff seem to have received formal training as all information and communication are consistent between staff and it is handed out leaflets to parents together with that there are posters in the department showing that $\mathrm{KC}$ is implemented at the unit. In our study the parents experience are that preparation strengthening the parental role as well as that the environment is prepared for $\mathrm{KC}$ to make it possible to come close to the infant. WHO [9] state that every health care facility that implements $\mathrm{KC}$ should develop written policy and guidelines that incorporate clear criteria for selection, monitoring and evaluation. Nykvist et al. [10] describe the evidence based recommendations for $\mathrm{KC}$ regarding knowledge and skills for staff nurses and what the information and communication should include to encourage and motivate parents to provide KC. MacCleary and Brown [30] suggest that for developing joint strategies for care in a hospital, there must be an interest from hospital management to support the staff nurses so that all staff are involved in achieving consistent caring.

All parents in our study provided KC in spite of that in two of the hospitals there is no common policy or procedures for KC. The parents experienced that all staff nurses have their own way to provide the KC. According to Higgs et al. is "professional practice without theory underpinning a guesswork" as parents in our study to some extent experience [31, p. 4]. The parents need gradually participation and confidence in $\mathrm{KC}$ before providing $\mathrm{KC}$.
The parents providing $\mathrm{KC}$ without these needs, being met in the yearning to get to know their infant but with a fear that the infant could be harmed or exposed to suffering. Through $\mathrm{KC}$ the parents experienced connection to their infants that also is confirmed in many other studies [12-19]. It is obvious that although the parents value the $\mathrm{KC}$ experience in our study they need attention and assistance from staff nurses to alleviate any of their anxieties and enhance the development of their parental role $[12-16,19,21,32,33]$. In the Irish quantitative study by Flynn \& Leahy-Warren [32] including 75 neonatal nurses who were implementing $\mathrm{KC}$ in their practical work and had a positive belief about the method, it was showed that none of the nurses had received any formal training or education in KC. In spite of the fact that all hospitals in our study have implemented $\mathrm{KC}$ as a caring method it seems as only staff nurses in one of the hospitals had received formal and clinical training in $\mathrm{KC}$, based on parents' statements that the staff had infused the feeling that $\mathrm{KC}$ was a substitute for the uterine enclosing and life-giving environment. In retrospect, the lack of staff training in $\mathrm{KC}$ leads to that parents feel that if they had received information about how important $\mathrm{KC}$ was for the infant, both medically and developmental, they would have demanded to provide $\mathrm{KC}$ more regularly. At least it should have been written information when the staff nurses seemed to have difficulty getting time with $\mathrm{KC}$ preparations.

When the infant is transferred to another hospital and the parents have provided $\mathrm{KC}$ in the first hospital, parents experience that $\mathrm{KC}$ has not the same routine at the "new hospital". The staff nurses do not gradually prepare the parents neither inform about the procedures for $\mathrm{KC}$ or communicate with the parents about how they have provided KC. Parents felt uncomfortable and lost their faith to provide $\mathrm{KC}$ in a sense of insecurity but did not communicate their feelings to the staff nurses. This phenomenon is interpreted by Lundqvist and Nilstun [34] as that when parents find themselves in a vulnerable position they do not stand up for themselves or their infants, but adapts to the staff's attitude, even if the attitude is offensive and should not be accepted in a different situation.

A few mothers experienced alienation to the infant in connection with the $\mathrm{KC}$ and provided the $\mathrm{KC}$ as a routine that was performed on the staff's request. Tessier et al. [35] also found that some mothers experienced isolation and a feeling of too much responsibility when providing KC. In Thernström Blomqvist \& Hedberg Nykvist [15] study had no mothers had this feeling, and the researchers believed it may be due to that the father in their study shared the task of KC with the mothers. The experience of alienation may also be due to that it is not uncommon that mothers of preterm infants have trouble bonding with their infants [36]. This is something that staff nurses need to be aware of.

One mother expressed some concerns about that the father provides $\mathrm{KC}$ before the mother in a sense of that the father got a deeper connection to the infant than the mother. Fegran, Helseth and Fagermoen [37] confirm that in such cases the fathers get a relationship with the infant and a protective instinct. This issue has to be further examined regarding if it has consequences for the mother-child attachment. 
Clinical implications for health care is that comprehensive education based on up to date research evidence detailing the benefits and risks of $\mathrm{KC}$ could be incorporated into new staff induction, and continuing education. Organisational support is needed to continuing education and to develop practice guidelines and protocols, to ensure the standardisation of information for parents and staff.

\section{DISCUSSION OF METHOD}

Regarding trustworthiness the parents narrated vividly and richly about their experiences and the interviewers checked their understanding with follow-up questions. To add depth and insight to the interpretation, the findings were discussed at research seminars. Quotes from the interviews are used to verify that the findings were retrieved from the data. The initial limitation of the study is that it is a retrospective study and it is found that parents have difficulties remembering information and communication about $\mathrm{KC}$ due to that they are shocked after giving birth to a preterm infant. A prospective study in the form of an observational study might provide what is really going on related to both the information and communication the staff provide and what families are experiencing. During the analysis the authors realised that some interviews, to a great extent, was about the delivery that was not in agreement with the aim of the study. The main reason for this was the insufficient experience of the interviewers in carrying out interviews. However, in total the whole texts from the interviews included lots of meanings of the studied phenomenon. The seven families with Swedish origin and the other five families consisting of one parent originating from another European country can be an advantage as Sweden is a multicultural country. Another shortcoming of the study is that the authors became more aware of the education that each neonatal unit had regarding the KC. A survey of training programs in the $\mathrm{KC}$ on neonatal units in Sweden needs to be explored.

\section{CONCLUSION}

For parents who participated in the study, the motive for practising $\mathrm{KC}$ was the desire to get close to their infant. Most of the parents had positive experience of KC. The information and communication from the staff gave courage and motivation for the parents to practice $\mathrm{KC}$ when the staff was well versed in the method and was coherent and supportive but gave conflicting emotions when the staff practised $\mathrm{KC}$ as a routine without deeper insight into the method's advantages and application. The challenge is to encourage neonatal staff nurses and hospital management to develop a written policy and guidelines that incorporate knowledge and skills to facilitate $\mathrm{KC}$ and give accurate and supportive information and communication to parents. Another challenge is to survey the education and training program that neonatal units offer the neonatal staff nurses in Sweden about KC.

\section{CONFLICT OF INTEREST}

The authors confirm that this article content has no conflict of interest.

\section{ACKNOWLEDGEMENTS}

The authors wish to thank the parents who participated in the study and devotedly shared their experience.

\section{REFERENCES}

[1] Socialstyrelsen, 2011a. Graviditeter, förlossningar och nyfödda barn - Medicinska födelseregistret 1973-2009 - Assisterad befruktning 1991-2008. Stockholm: Socialstyrelsen (sid, 44). [In English: National Board of Health and Welfare, 2011a. Pregnancies, births and newborns - Medical Birth Register, 19732009 - Assisted reproduction 1991-2008. Stockholm: National Board of Health and Welfare 2011a; p. 44.

[2] Beck S, Wojdyla D, Say L, et al. The worldwide incidence of preterm birth: a systematic review of maternal mortality and morbidity. Bull World Health Organ 2010; 88: 31-8.

[3] Socialstyrelsen, 2011b. Sveriges officiella statistik. Hälso- och sjukvård. Publiceringsår 2011. Bilaga 1 Graviditeter, förlossningar och nyfödda barn. Medicinska födelseregistret, 1973-2009. Stockholm: Socialstyrelsen. In English: National Board of Health and Wellfare, 2011a. Official statistics of Sweden. Health care. Publication 2011th Appendix 1 pregnancies, births and newborns. Medical Birth Register, 1973-2009. Stockholm: National Board of Health and Welfare, 2011b.] Available from: http://www.socialsty relsen.se/publikationer2011.2011-3-19/Documents/Bilaga\%201.pdf

[4] Danerek M, Dykes A-K. A theoretical model of parents' experiences of threat of preterm birth in Sweden. Midwifery 2008; 24(4): 416-24.

[5] Lindberg B, Ohrlin K. Experiences of having a prematurely born infant from the perspective of mothers in northern Sweden. Int $J$ Circumpolar Health 2008; 67(5): 461-71.

[6] Lundqvist P, Westas LH, Hallstrom I. From distance toward proximity: Fathers' lived experience of caring for their preterm infants. J Pediatr Nurs 2003; 22(6): 490-7.

[7] Flacking R, Ewald U, Nykvist Hedberg K, Starrin B. Trustful bonds: A key to "becoming a mother' and to reciprocal breastfeeding. Stories of mothers of very preterm infants at a neonatal unit. Soc Sci Med 2006; 62: 70-80.

[8] Wigert H, Johansson R, Berg M, Hellström AL. Mothers' experiences of having their newborn child in a neonatal intensive care unit. Scand J Caring Sci 2006; 20(1): 35-41.

[9] WHO. Kangaroo Mother Care: A practical guide. Geneva: World Health Organization 2003.

[10] Nyqvist KH, Andersson GC, Bergman N, et al. Towards universal Kangaroo Mother Care: recommendations and report from the First European conference and Seventh International Workshop on Kangaroo Mother Care. Acta Paediatr 2010; 99(6): 820-6.

[11] Cattaneo A, Davanzo R, Uxa F, Tamburini G. Recommendations for the implementation of Kangaroo Mother Care for low birthweight infants. International Network on Kangaroo Mother Care. Acta Pediatr 1998; 87(4): 440-5.

[12] Neu M. Parents' perception of skin-to-skin care with their preterm infants requiring assisted ventilation. J Obstet Gynecol Neonatal Nurs1999; 28(2): 157-64.

[13] Roller CG. Getting to know you: mothers' experiences of Kangaroo Care. J Obstet Gynecol Neonatal Nurs 2005; 34(2): 2107.

[14] Leonard A, Mayers P. Parents' lived experience of providing kangaroo care to their preterm infants. J Interdiscip Health Sci 2008; 13(4): 16-28.

[15] Thernström BY, Hedberg NK. Swedish mothers' experience of continues Kangaroo Mother Care. J Clin Nurs 2010; 20(9- 10): 1472-80.

[16] Thernström BY, Rubertsson C, Kylberg E, Jöreskog K, Hedberg NK. Kangaroo Mother care helps fathers of preterm infants gain confidence in the parental role. J Adv Nurs 2011; 68(9): 1988-96.

[17] Dalbye R, Calais E, Berg M. Mothers' experiences of skin-to-skin care of healthy full-term newborns - A phenomenology study. Sex Reprod Healthc 2011; 2: 107-11.

[18] Tallandini MA, Scalembra C. Kangaroo Mother Care and motherpremature infant dyadic interaction. Infant Ment Health J 2006; 27: 251-75.

[19] Nagorski Johnson A. The maternal experience of kangaroo holding. J Obstet Gynecol Neonatal Nurs 2007; 36: 568-73.

[20] Erlandsson K, Christensson K, Fagerberg I. Fathers' lived experiences of getting to know their baby while acting as primary 
caregivers immediately following birth. J Perinat Educ 2008; 17 : 28- 36.

[21] Johnston CC, Stevens B, Pinelli J, et al. Kangaroo care is effective in diminishing pain response in preterm neonates. Arch Pediatr Adolesc Med 2003; 157: 1084-8.

[22] Ludington-Hoe SM, Johnson MW, Morgan K, et al. Neurophysiologic assessment of neonatal sleep organization: preliminary results of a randomized, controlled trial of skin contact with preterm infants. Pediatrics 2006; 117: e909-23.

[23] Flacking R, Ewald U, Wallin L. Positive effect of kangaroo mother care on long term breastfeeding in very preterm infants. J Obstet Gynecol Neonatal Nurs 2011; 40(2): 190-7.

[24] Lawn EJ, Mwansa-Kambafwile J, Horta BL, Barros FC, Cousens S. 'Kangaroo mother care' to prevent neonatal deaths due to preterm birth complications. Int J Epidemiol 2010; 39(Suppl 1): i144-54.

[25] Lincoln YS, Guba EG. Naturalistic inquiry. Canada: Newbury Park, Sage Publications 1985.

[26] Socialstyrelsen 2004. Perinatalt omhändertagande vid underburenhet. (Artikelnummer 2004-123-15). (In English: National Board of Health and Wellfare. Perinatal caring of pretrem infants 2004. Article number: 2004-123-15.

[27] Graneheim UH, Lundman B. Qualitative content analysis in nursing research: concepts, procedures and measures to achieve trustworthiness. Nurse Educ Today 2004; 24(2): 105-12.

[28] Krippendorff K. Content analysis. An introduction to its methodology. London: The Sage Commtext Series, Sage Publications Ltd. 1980.
[29] World Medical Association Declaration of Helsinki [WMA] 2008 Available from: http:/www.wma.net/en/30publications/10policies/ b3/17c.pdf

[30] McCleary L, Brown G. Barriers to paediatric nurses' research utilization. J Adv Nurs 2003; 42(4): 364-72.

[31] Higgs J, Titchen A, Neville V. Professional practice and knowledge. In: Higgs J, Titchen A, Eds. Practice knowledge and expertise in the health professions. Oxford: Butterworth Heinemann 2001; p. 3-9.

[32] Flynn A, Leahy-Warren P. Neonatal nurses' knowledge and beliefs regarding kangaroo care with preterm infants in an Irish neonatal unit. J Neonatal Nurs 2010; 14: 221-8.

[33] Moran M, Radzyminski SG, Higgins KR, Dowling DA, Miller MJ Anderson GC. Maternal kangaroo (skin-to-skin) care in the NICU beginning 4 hours postbirth. MCN Am J Matern Child Nurs 1999; 24(2): 74-9.

[34] Lundqvist A, Nilstun T. Human ethics in paediatrics: the effects in health care. Nurs Ethics 2007; 14(2): 215-28.

[35] Tessier R, Cristo M, Velez S, et al. Kangaroo mother care and the bonding hypothesis. Pediatrics 1998; 102(2): e 17.

[36] Niven C, Wisznirwski C, AlRoomi L. Attachment (bonding) in mothers of pre-term babies. J Reprod Infant Psychol 1993; 11: 17585.

[37] Fegran L, Helseth S, Fagermoen S. A comparison of mothers' and fathers' experiences of the attachment process in an neonatal intensive care unit. J Clin Nurs 2008; 17(6): 810-6. 